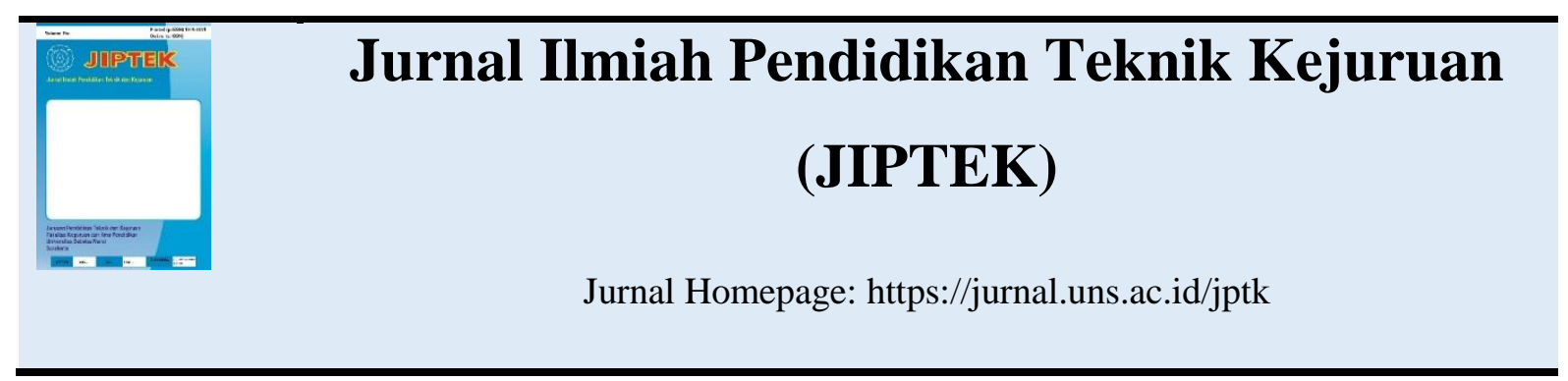

\title{
RANCANG BANGUN ALARM FOKUS UNTUK MEMBANTU MENINGKATKAN KONSENTRASI SISWA SAAT BELAJAR
}

\author{
Deny Nusyirwan ${ }^{1}$, M. Aris Akbar ${ }^{2}$, Prasetya Perwira Putra Perdana ${ }^{3}$ \\ 1,2,3 Jurusan Teknik Eektro, Fakultas Teknik, Universitas Maritim Raja Ali Haji (UMRAH) \\ Jl. Politeknik Senggarang, Tanjungpinang 29100 \\ Email: denynusyirwan@umrah.ac.id
}

\begin{abstract}
ABSTRAK
Konsentrasi sangat penting dan sangat dibutuhkan bagi siswa dalam mengikuti proses pembelajaran agar kompetensi yang diharapkan dapat dikuasai dan tercapai dengan baik. Pentingnya konsentrasi bagi siswa merupakan proses bagi siswa untuk dapat belajar dan berhasil mencapai tujuan pembelajaran. Dari hasil observasi didaptkan permasalahan utama yang dapat mengganggu konsenstrasi siswa ketika sedang belajar didalam kelas, yaitu siswa ribut atau berbicara dengan rekannya ketika guru menerangkan pelajaran. Dengan latar belakang tersebut diperlukan sebuah inovasi yang berbasiskan teknologi mikrokontroler yang dinamakan Alarm Fokus. Alarm akan berbunyi ketika guru menekan saklar tekan sehingga siswa akan kembali konsentrasi pada pelajaran. Penelitian ini memanfaatkan design thinking dengan pendekatan proses desain rekayasa konsep Double Diamond yang diperkenalkan oleh British Design Council. Dimulai dengan etnografi di SDN 003 Binaan Tanjungpinang Kota, observasi dan wawancara dengan siswa, brainstorming terhadap permasalahanpermasalahan yang ditemukan di sekolah, dan berdiskusi untuk menentukan permasalahan utama. Dari hasil uji fungsi dan pengujian kegunaan menunjukkan bahwa purwarupa yang dihasilkan dapat berfugsi dengan baik dan calon pengguna juga memberikan tanggapan yang memuaskan.
\end{abstract}

Kata kunci: konsentrasi, siswa, mikrokontroler, etnografi

\begin{abstract}
Concentration is very important and very necessary for students to follow the learning process so that the competencies that are expected can be mastered and achieved well. The importance of concentration for students is a process for students to be able to learn and successfully achieve learning goals. From the results of the observations, the main problems that can interfere with the concentration of students when learning in the classroom are the students who are noisy or talk to their peers when the teacher explains the lesson. With this background an innovation based on microcontroller technology called Alarm Focus is needed. The alarm will sound when the teacher presses the push switch so students will return to concentration on the lesson. This study utilizes design thinking with the Double Diamond concept engineering design approach which was introduced by the British Design Council. Starting with ethnography at SDN 003 Binaan Tanjungpinang Kota, observation and interviews with students, brainstorming of problems found at school, and discussing to determine the main problem. From the results of the functional test and usability testing shows that the prototype produced can function well and potential users also provide satisfactory responses.
\end{abstract}

Keywords: concentration, student, microcontroller, ethnography

\section{PENDAHULUAN}

JIPTEK, Vol. 14 No. 1, 2021

DOI: https://dx.doi.org/10.20961/jiptek.v14i1.34573 
Konsentrasi adalah kondisi dan kemampuan seseorang yang dengan kesadarannya dapat memusatkan perhatian (melibatkan alat indra) pada situasi yang sedang dihadapinya. Bagi siswa pemusatan perhatian yang dimaksudkan di sini tentu dalam hal mengikuti proses belajar. Lalu bagaimana jika siswa bisa berkonsentrasi tetapi hanya terhadap dirinya sendiri, bukan berkonsentrasi pada situasi yang sedang dihadapinya, inilah masalah yang selalu dihadapi siswa. Konsentrasi juga sering dijadikan sebagai alasan jika siswa tidak dapat menguasai materi pelajaran yang diajarkan guru saat proses pembelajaran berlangsung.

Sulit untuk mengetahui keadaan atau tanda-tanda siswa sedang berkonsentrasi atau tidak. Hanya individu sendiri yang dapat mengetahui apakah dirinya sedang dalam berkonsentrasi atau tidak. Lebih jauh lagi siswa tersebut pun bisa saja tidak menyadari bahwa sebenarnya dalam keadaan berkonsentrasi. Konsentrasi sangat penting dan dibutuhkan bagi siswa dalam mengikuti proses pembelajaran agar kompetensi yang diharapkan dapat dikuasainya bisa tercapai dengan baik. Begitu pentingnya konsentrasi bagi siswa, sehingga konsentrasi adalah merupakan prasyarat bagi siswa agar dapat belajar dan berhasil mencapai tujuan pembelajaran.

Pendidikan sangat penting bagi kita, negara bisa maju karena orang-orangnya berpendidikan. Keberhasilan pendidikan ditentukan oleh kualitas pendidikan itu sendiri. Untuk mengetahui kualitas pendidkan diperlukan suatu hasil atau prestasi. Salah satu faktor yang mempengaruhi prestasi adalah fasilitas (Muhamad, Efendi dan Basori,
2019, p 56-64). Selain fasilitas belajar tersebut, manajemen kelas juga sebagai faktor yang diduga mempengaruhi prestasi belajar siswa, analisis secara simultan menunjukkan korelasi yang kuat antar keduanya (Anggraini dan Imaniyati, 2017, p 196-204).

Fasilitas belajar berperan mempermudah dan memecahkan masalahmasalah yang timbul sewaktu mempelajari dan memahami pelajaran atau tugas yang diberikan oleh guru. Fasilitas belajar ini meliputi sarana dan prasarana yang dalam belajar.( Tirani A A, 2017, p 59-66)

Dapat ditemukan dalam observasi di SDN 003 Binaan Tanjungpinang Kota, ketika proses belajar di dalam kelas yang berlangsung cukup lama akan membuat konsentrasi siswa menurun sehingga pengetahuan yang didapat akan lebih sedikit dari awal pelajaran dimulai. Selain itu, guru-guru yang mengajar juga masih mengalami kesulitan untuk mengatur siswa didalam kelas disebabkan karena faktor usia guru dan jumlah siswa didalam kelas yang ramai. Oleh karena itu dalam penelitian ini ditemukan sebuah masalah yaitu kurangnya konsentrasi siswa didalam belajar. Untuk mengatasi permasalahan ini, diperlukan sebuah fasilitas di sekolah yang berupa inovasi berbasiskan teknologi yang dinamakan Alarm Fokus, yang bertujuan untuk membantu meningkatkan konsentrasi siswa saat proses pembelajaran dengan cara menjaga siswa agar tetap berkonsentrasi terutama pada saat proses belajar sedang berlangsung.

\section{Penelitian terdahulu}

Beberapa penelitian terdahulu sudah dilakukan untuk membantu meningkatkan 
konsenstrasi siswa ketika sedang belajar didalam kelas.

Penelitian yang dilakukan oleh Valouch (December 2012), dengan judul penelitian Integrated Alarm Systems menjelaskan mengenai Sistem alarm adalah bagian dari sumber daya teknis untuk memberikan dukungan bagi kelangsungan bisnis. Sistem alarm yang terintegrasi adalah cara modern yang menggunakan kemampuan teknologi saat ini dari sistem alarm penyusup, CCTV, kontrol akses dan sistem alarm penahan. Aplikasi ini dapat diintegrasikan satu sama lain atau untuk melengkapi sistem non-alarm dan dengan demikian menyediakan proses otomasi dalam bangunan komersial dan perumahan. Penelitian ini membahas masalah solusi teknis alarm interkoneksi dan sistem non-alarm. Output utama dari penelitian ini adalah klasifikasi teknik integrasi sistem ini (Valouch, 2012),

Sedangkan pada penelitian yang dilakukan oleh Us, Jensen, Lind dan Jorgensen (2011) dengan judul Fundamental Principle of Alarm Design, menjelaskan secara tradisional alarm dirancang berdasarkan pedoman empiris dan bukan pada bunyi kerangka kerja ilmiah bersumber pada landasan teori untuk proses dan desain sistem kontrol. Kertas ini mengusulkan prinsip-prinsip ilmiah dan metodologi untuk merancang alarm berdasarkan teknik pemodelan fungsional (MFM) yang mewakili proses dalam hal tujuan, fungsi, dan persyaratan operasi. Alasannya kemampuan MFM memungkinkan identifikasi situasi operasional yang mengancam untuk menghasilkan alarm dan derivasi skenario respons potensial. Metodologi desain dapat diterapkan pada sistem rekayasa apa pun yang dapat dimodelkan oleh MFM. Metodologi ini menyediakan satu set alarm yang dapat memfasilitasi acara interpretasi dan dukungan operator untuk manajemen situasi abnormal. Metodologi desain yang diusulkan menyediakan konten informasi alarm, tetapi tidak berurusan dengan presentasi alarm atau desain tampilan masalah. Proses penggilingan bertenaga hidrolik digunakan sebagai sistem yang relevan secara industri untuk menunjukkan penerapan metodologi desain yang diusulkan dengan hasil yang menjanjikan (Us, Jensen, Lind dan Jorgensen, 2011, p 44-51 ).

Penelitian yang dilakukan oleh Bliss dan Chancey (2010) dengan judul The Effects of Alarm System Reliability and Reaction Training Strategy on Alarm Responses,yaitu penelitiannya menunjukkan bahwa manusia bereaksi secara tak terduga terhadap sistem alarm yang tidak dapat diandalkan dan bahwa beberapa variabel dapat memediasi hubungan antara keandalan dan kinerja alarm. Para peneliti telah mengidentifikasi desain alarm dan strategi pelatihan operator untuk meningkatkan reaksi operator tugas. Tujuan proyek saat ini adalah untuk melatih para pelaku tugas untuk menggunakan pola aktivitas sensor untuk meningkatkan reaksi alarm selanjutnya. Delapan puluh peserta memantau layar keamanan yang disimulasikan sambil menyelesaikan tugas pencarian kata utama. Selama sesi keandalan rendah dan alarm tinggi, sensor gerak diaktifkan di berbagai ruangan, yang membutuhkan pengakuan. Alarm kemudian diaktifkan, mengharuskan peserta untuk merespons atau mengabaikannya. Peserta menerima spasial, 
temporal, sensor tunggal, atau tidak ada pelatihan. Mereka juga menyadari tingkat keandalan sistem alarm. Analisis mengungkapkan reaksi yang lebih cepat untuk peserta yang terlatih dan alarm keandalan yang tinggi. Hasil menunjukkan bahwa pelatihan sensor tunggal adalah yang paling bermanfaat dan bahwa peserta yang menerima pelatihan sementara bergantung pada keandalan alarm sebagai isyarat (Bliss dan Chancey, 2010, p 2248-2252)

Penelitian yang dilakukan oleh Shergian dan Immawan(2014) dengan judul Design of Innovative Alarm Clock Made From Bamboo With Kansei Engineering Approach,menjelaskan bahwa sebelumnya, "Othok-othok" mainan tradisional bambu dan jam alarm memiliki penjualan tinggi, tetapi sebagai dampak dari pengembangan produk modern, kedua penjualan menurun. Inovasi jam alarm yang terbuat dari bambu sebagai sumber bunyi adalah salah satu solusi alternatif dari kedua produk yang menurun. Metode Kansei Engineering digunakan untuk mengubah perasaan dan imajinasi pelanggan menjadi parameter desain. Hasil dari penelitian ini adalah jam alarm inovatif yang memuaskan perasaan pelanggan psikologis. (Shergian dan Immawan, 2014, p 184-188)

\section{METODE PENELITIAN}

Desainer memainkan peran strategis dalam inovasi dan proses transisi menuju masyarakat yang berkelanjutan. Desainer bertindak di semua lapisan masyarakat dan membutuhkan bantuan untuk menemukan jalan melalui sistem inovasi yang semakin saling terkait (Joore, dan Brezet,
2015, p 92-105), Desain dan kreativitas menjadi keterampilan yang sangat dicari dalam industri terkemuka di seluruh dunia, perusahaan besar mengembangkan "Chief Design Officer" untuk terlibat dengan diskusi strategis dan sebagai pendorong ekonomi perusahaan, oleh sebab itu diperlukan menanamkan "kreativitas" ke dalam pendidikan tingkat sekolah menengah dan universitas untuk mendorong inovasi dan pengembangan tingkat selanjutnya (Collins, 2015, p 258-262).

Selama siklus proses perancangan rekayasa, rekayasawan diharapkan untuk sepenuhnya memahami kebutuhan pelanggan walaupun menghadapi tantangan berupa geografis, jadwal proyek yang sempit, atau anggaran yang pendek (Pereira dan Russo, 2018, p 775-782). Proses Desain Rekayasa adalah merupakan sebuah proses didalam mendesain dengan berpusat kepada pengguna. dimulai dengan etnografi hingga menghasilkan sebuah purwarupa yang merupakan sebuah konsep solusi yang sesuai dengan kebutuhan di masyarakat.

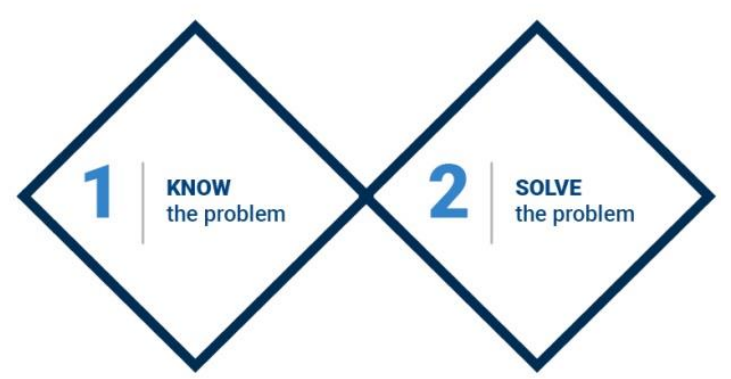

Gambar 1. Tahapan pada Proses Desain Rekayasa (https://resources.mygov.scot/)

Proses ini memiliki 4 tahapan, pada tahapan awal dimulai pelaksanaan observasi secara luas di masyarakat untuk mendapatkan permasalahan-permasalahan, dalam tahapan ini 
peneliti berusaha untuk mampu mengalami emosi dan mengetahui apa yang dipikirkan oleh calon pengguna. Tahapan kedua adalah proses pengerucutan dengan melakukan pemilihan permasalahan utama, tahapan ketiga adalah mengembangkan ide-ide sebagai solusi terhadap permasalahan utama untuk mendapatkan solusi utama sehingga dapat dilanjutkan ke tahapan pembuatan purwarupa dengan memperhatikan bahwa purwarupa yang dihasilkan sederhana dan mudah dirubah. Tahapan terahir adalah pengujian, bertujuan untuk mengetahui kinerja dari purwarupa dan mendapatkan masukan untuk perbaikan inovasi apabila diperlukan nantinya.

Lokasi penelitian dilakukan di SDN 003 Binaan Tanjungpinang, Kepulauan Riau, lihat Gambar

2.
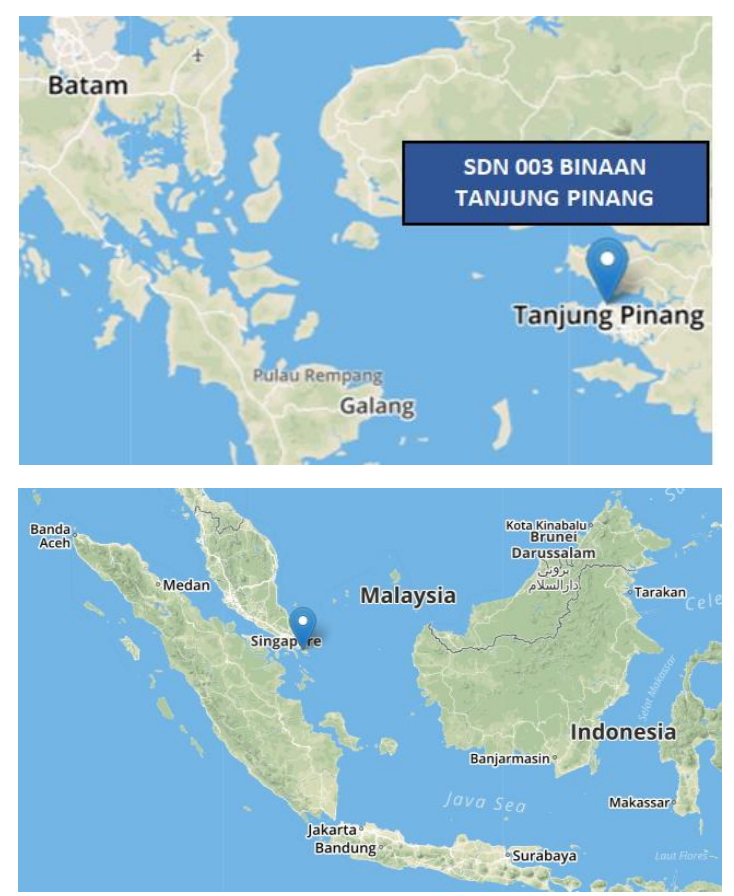

Gambar 2. Lokasi SDN 003 Tanjungpinang (http://referensi.data.kemdikbud.go.id/) Langkah awal dari Proses Perancangan

Rekayasa, yang merupakan aktivitas pegamatan atau observasi secara langsung ke masyarakat di suatu daerah untuk mendapatkan data yang akurat sehingga mampu menghasilkan sebuah solusi yang tepat.

\section{Proses Etnografi}

Adapun metode observasi yang dipergunakan adalah metode observasi Peserta sebagai peneliti (participant as observer), pada metode ini peneliti ikut serta didalam kelompok yang sedang diteliti, berpartisipasi aktif mengikuti kegiatan dan aktivitas. Kelompok yang sedang diteliti mengetahui mengenai penelitian. Dengan metode ini maka peneliti dan kelompok yang diteliti akan lebih lebih dekat dan terbuka sehingga timbul saling percayaan, pada ahirnya akan memberikan informasi yang lebih dalam (Wagner, Kawulich, and Garner, 2012).
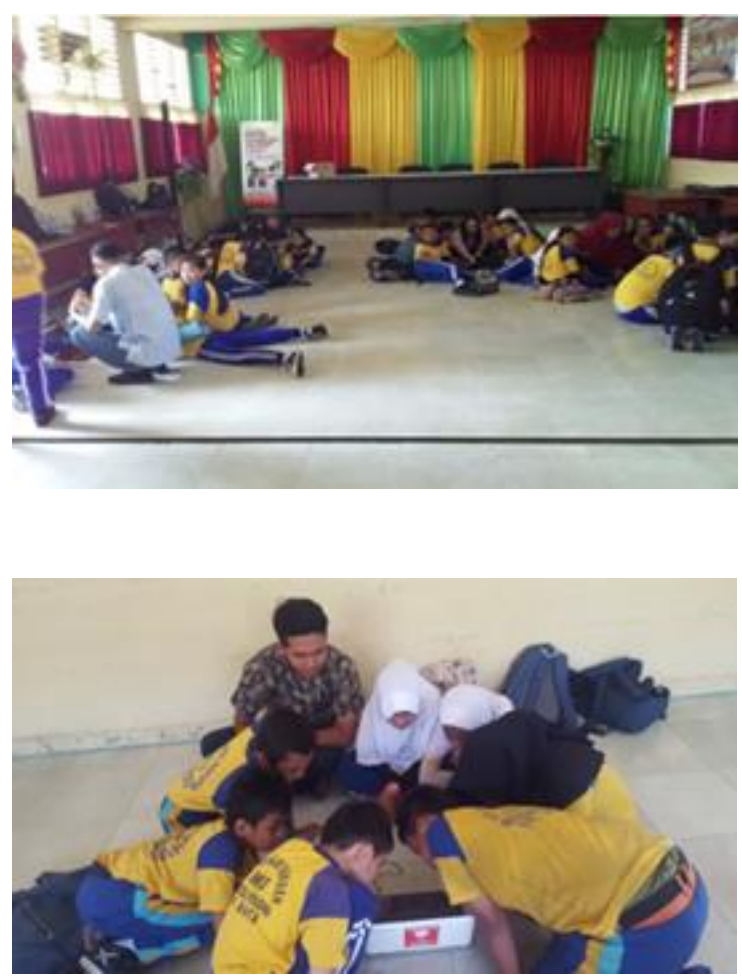

Gambar 3. Suasana di SDN 003 Binaan Tanjung Pinang 
Pada Gambar 3 menampilkan keadaaan di SDN 003 Tanjung Pinang untuk mendapatkan data-data yang di perlukan dengan metode etnografi. Dengan pendekatan ini diharapkan penelitian akan mendapatkan informasi secara luas mengenai permasalahan-permasalahan pada lokasi penelitian.

\section{HASIL PENELITIAN}

Tahapan selanjutnya adalah curahan gagasan permasalahan yang ditemukan di sekolah dari hasil observasi, dimana semua permasalahan yang ditemukan akan di dokumentasikan. Proses ini adalah merupakan tahapan yang penting, karena sangat diharapkan bahwa solusi yang akan dihasilkan adalah merupakan solusi yang dibutuhkan, bukan solusi yang diminta oleh calon pengguna. Pola penyampaian gagasan secara bebas akan sangat diperlukan untuk memotivasi peneliti untuk mampu berpikir inovatif dan kreatif.

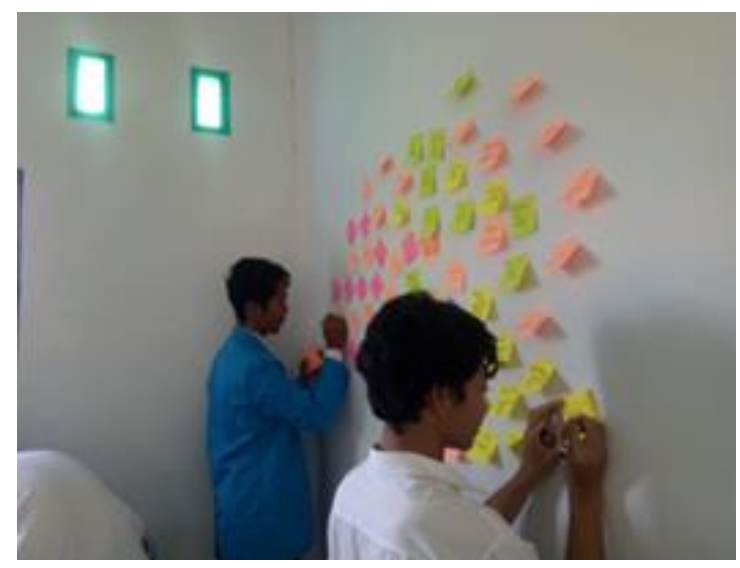

Gambar 4. Proses pengumpulan masalah

Curahan gagasan yang bersifat luas adalah merupakan pondasi bagi rekayasawan untuk mampu menghasilkan sebuah inovasi yang berbasiskan teknologi. Hal ini sering dipahami dengan $\mathrm{T}$ concept, dimaksudkan bahwa inovasi yang dihasilkan memiliki pengaruh yang luas dan mendalam. Pada Gambar 4 dapat dilihat proses pengumpulan masalah-masalah yang sangat berkaitan dengan kejadian di sekolah selama melakukan observasi dan wawancara.

Permasalahan utama adalah satu permasalahan yang akan dijadikan landasan untuk langkah penentuan solusi, dalam tahapan ini akan dilakukan proses pengerucutan masalah, dimulai dengan pengelompokan masalah dan selanjutnya di pilih satu masalah saja, lihat Gambar 5. Proses diskusi bersama sesama anggota kelompok dengan saling memberikan penjelasan terhadap masalah yang akan dijadikan masalah utama diperlukan untuk mendapatkan informasi-informasi yang belum dapat disampaikan pada tahapan sebelumnya. Adapun permasalahan utama dari penelitian ini adalah waktu untuk mendapatkan buku.

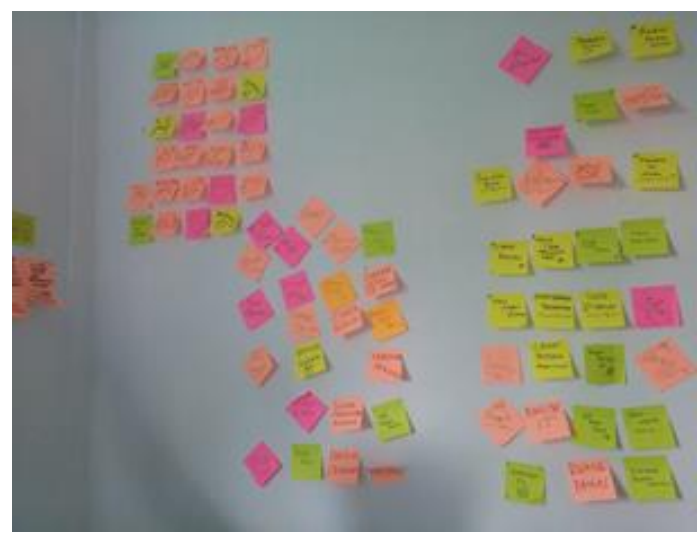

Gambar 5. Proses pengerucutan masalah untuk mendapatkan masalah utama

Tahapan curahan gagasan solusi dari masalah utama dilakukan setelah mendapatkan permasalahan utama. Dalam tahapan ini akan 
disampaikan beberapa konsep solusi bersama anggota peneliti lainnya. Dengan mempergunakan alat bantu berupa perangkat lunak tiga dimensi Autodesk Inventor. Pada Gambar 6 menampilkan sebuah konsep solusi utama berupa alarm fokus

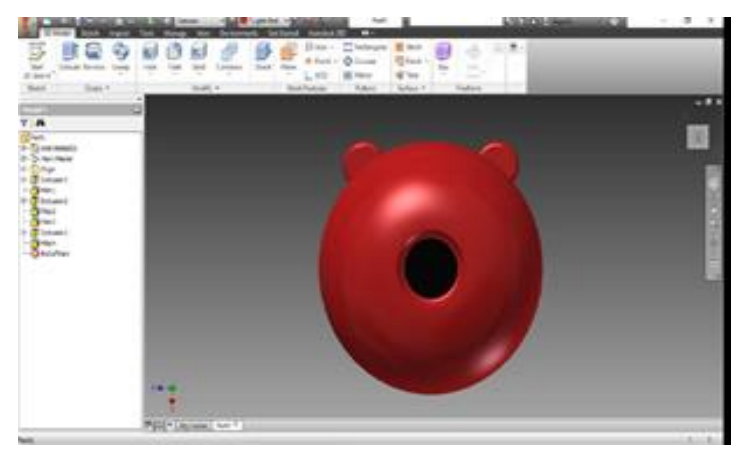

Gambar 6. Konsep solusi utama

\section{a. Purwarupa}

Tahapan yang sudah mulai memerlukan pembiayaan adalah tahapan pembuatan purwarupa. Oleh sebab itu pada Proses Perancangan Rekayasa ini, menekankan untuk mampu menghasilkan purwarupa sederhana yang ekonomis dan fleksible, dengan maksud bahwa perubahan rancangan dapat dilakukan dengan mudah dan tidak akan memerlukan pembiayaan yang besar. Purwarupa dalam tahapan ini lebih dikenal dengan istilah low resolution prototype (Nusyirwan, 2017, p.24-35) Dapat dilihat pada Gambar 7 adalah sebuah purwarupa sederhana dari rak buku otomatis.
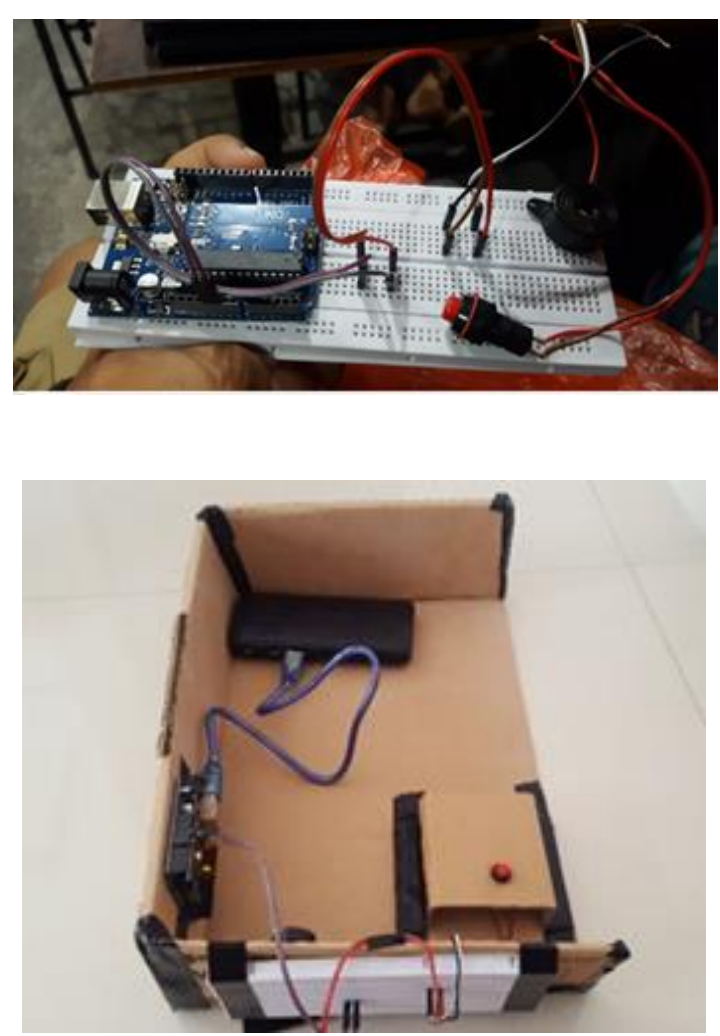

Gambar 7. Purwarupa Sederhana

Adapun komponen yang diperlukan untuk pembuatan purwarupa dengan estimasi harga adalah sila lihat pada Tabel 1.

Tabel 1. Estimasi anggaran ( Bukalapak, diakses 11 Agustus 2019)

\begin{tabular}{|c|c|c|c|c|}
\hline No. & Barang & 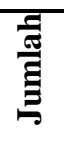 & : & $\stackrel{\bar{\pi}}{\stackrel{\theta}{\theta}}$ \\
\hline 1 & Arduino Uno & 1 & 80000 & 80000 \\
\hline 2 & Push Button & 1 & 4000 & 4000 \\
\hline 3 & Breadboard & 1 & 32000 & 32000 \\
\hline 4 & $\begin{array}{l}\text { Relay } 2 \\
\text { channel }\end{array}$ & 1 & 17000 & 17000 \\
\hline 5 & Buzzer & 1 & 5000 & 5000 \\
\hline \multirow[t]{2}{*}{6} & Kabel Jumper & 10 & 1000 & 10000 \\
\hline & Jumlah & & & 148000 \\
\hline
\end{tabular}

\section{Arduino UNO R3}

Arduino Uno R3 adalah merupakan sebuah mikrokontroller, dimana mikrokontroler 
tersebut akan memproses input yang diberikan melalui bahasa pemograman open source sehingga akan menghasilkan output. Cukup hubungkan Arduino dengan kabel USB ke PC atau Mac/Linux anda, jalankan software Arduino sudah bisa untuk memprogram chip ATmega328. Sila lihat Gambar 8.

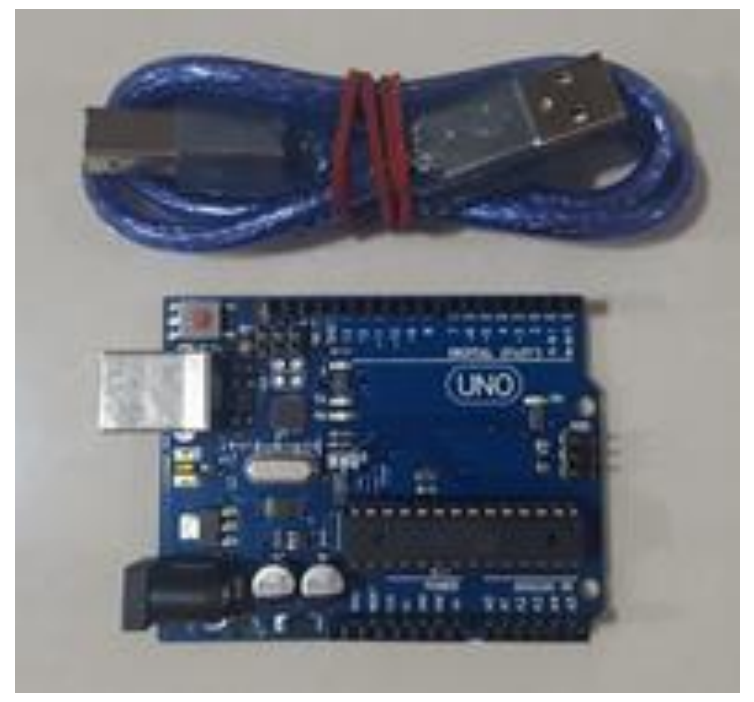

Gambar 8. Arduino Uno

\section{Breadboard}

Breadboard adalah merupakan papan ujicoba rangkaian elektronika yang pada umumnya dipergunakan oleh pemula yang ingin mencoba. Papan dengan konstruksi berlubang sesuai untuk menancapkan komponen tanpa di hubungkan secara permananen. Komponen yang telah dipergunakan pada satu rangkaian dapat dipergunakan kembali setelah dipergunakan sebalumnya, sila lihat Gambar 9.

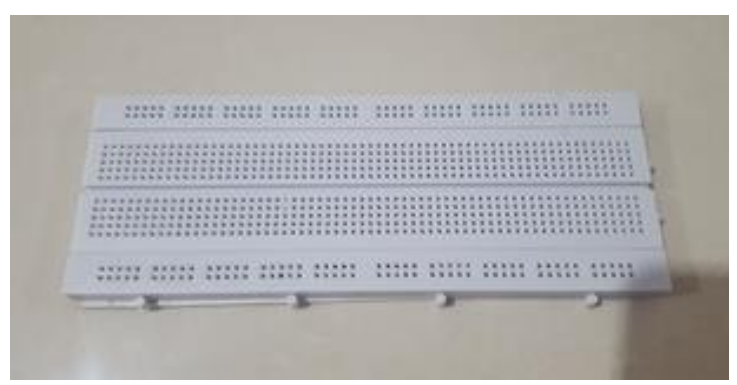

\section{Gambar 9. BreadBoard}

\section{Kabel jumper}

Kabel jumper adalah kabel yang di pergunakan untuk menghubungkan satu komponen dengan komponen lain ataupun menghubungkan jalur rangkaian yang terputus pada breadboard, sila lihat Gambar 10.

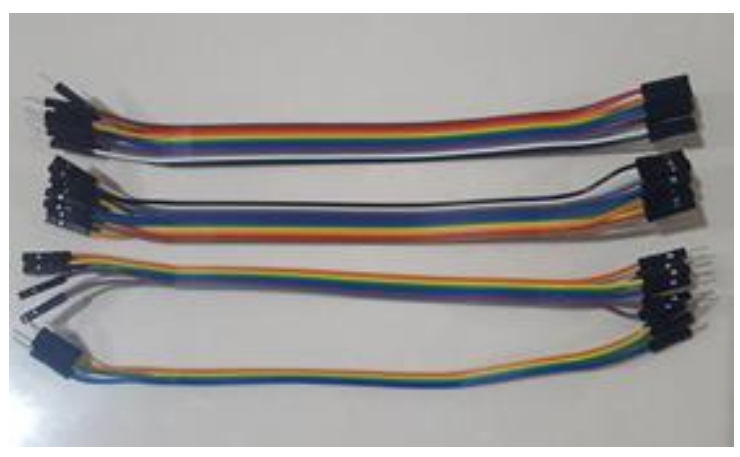

Gambar 10. Kabel Jumper

\section{Relay}

Relay adalah sebuah peralatan elektronika yang mengatur hidup dan mati dengan menggunakan elektromagrnetik. Prinsip kerjanya sama dengan sakkar manual yang akan menghubungkan dan memutuskan aliran listrik.Sila lihat Gambar 11 


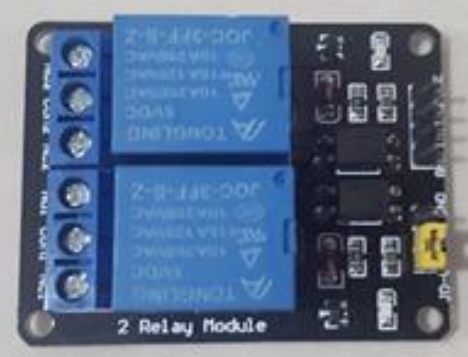

Gambar 11. Relay

\section{Push Button}

Saklar tombol tekan (push button switch) adalah perangkat / saklar sederhana yang berfungsi untuk menghubungkan atau memutuskan aliran arus listrik dengan sistem kerja tekan unlock (tidak mengunci). Sistem kerja unlock disini berarti saklar akan bekerja sebagai device penghubung atau pemutus aliran arus listrik saat tombol ditekan, dan saat tombol tidak ditekan (dilepas), maka saklar akan kembali pada kondisi normal, sila lihat Gambar 12

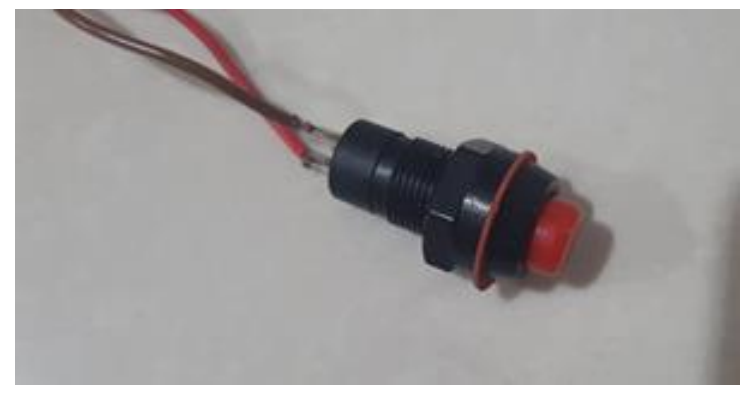

Gambar 12. Push Button

\section{b. Pengujjian Kegunaan}

Pengujian kegunaan adalah proses evaluasi terhadap inovasi yang dirancang dengan berbasis pengguna. Pada tahapan ini pengguna akan berpartisipasi dan berinteraksi secara langsung dengan purwarupa sederhana yang dihasilkan. Pengguna akan diminta untuk melakukan tugas tertentu atau hanya menjelajahinya secara bebas, sementara perilaku pengguna diamati dan dicatat untuk mengidentifikasi kelemahan desain yang menyebabkan kesalahan atau kesulitan pengguna. Setelah kelemahan desain telah diidentifikasi, rekomendasi desain diusulkan untuk meningkatkan kualitas ergonomis produk (Bastien, 2017, p e18-e23). Sila lihat Gambar 13.

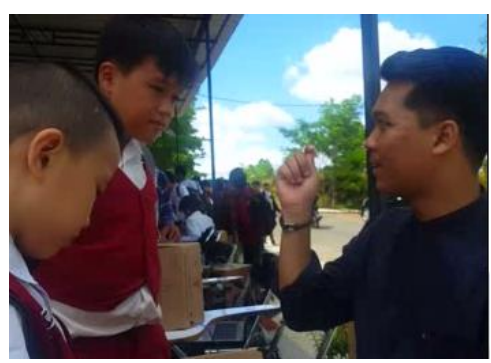

Tahapan awal pengujian dengan menjelaska $\mathrm{n}$ fungsi dan manfaat purawarupa kepada siswa

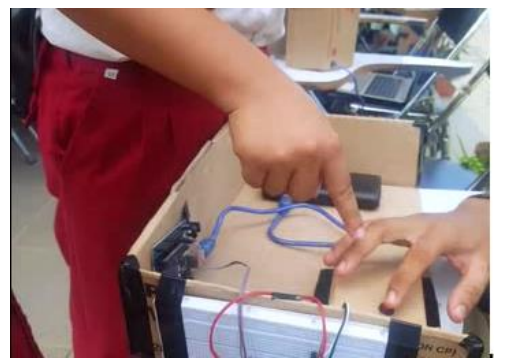

Siswa menguji purwarupa secara langsung

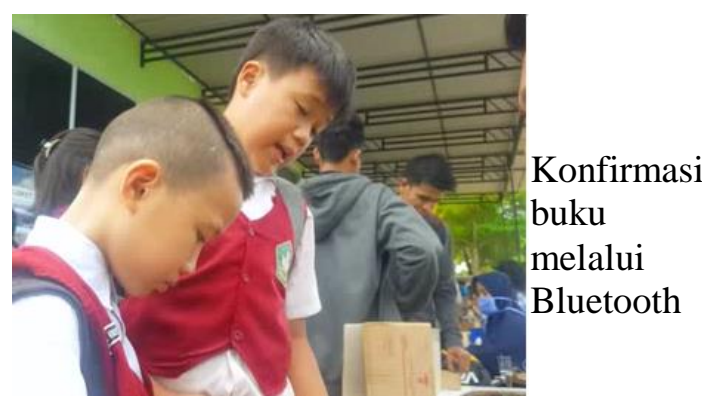

Gambar 13. Siswa memberikan informasi setelah melakukan pengujian

\section{c. Program pada Arduino}


Berikut adalah diagram rangkaian elektronika yang dipergunakan sebagai referensi untuk program yang ditulis pada Arduino untuk dapat menghasilkan luaran sesuai yang di inginkan. Sila lihat Gambar 14.
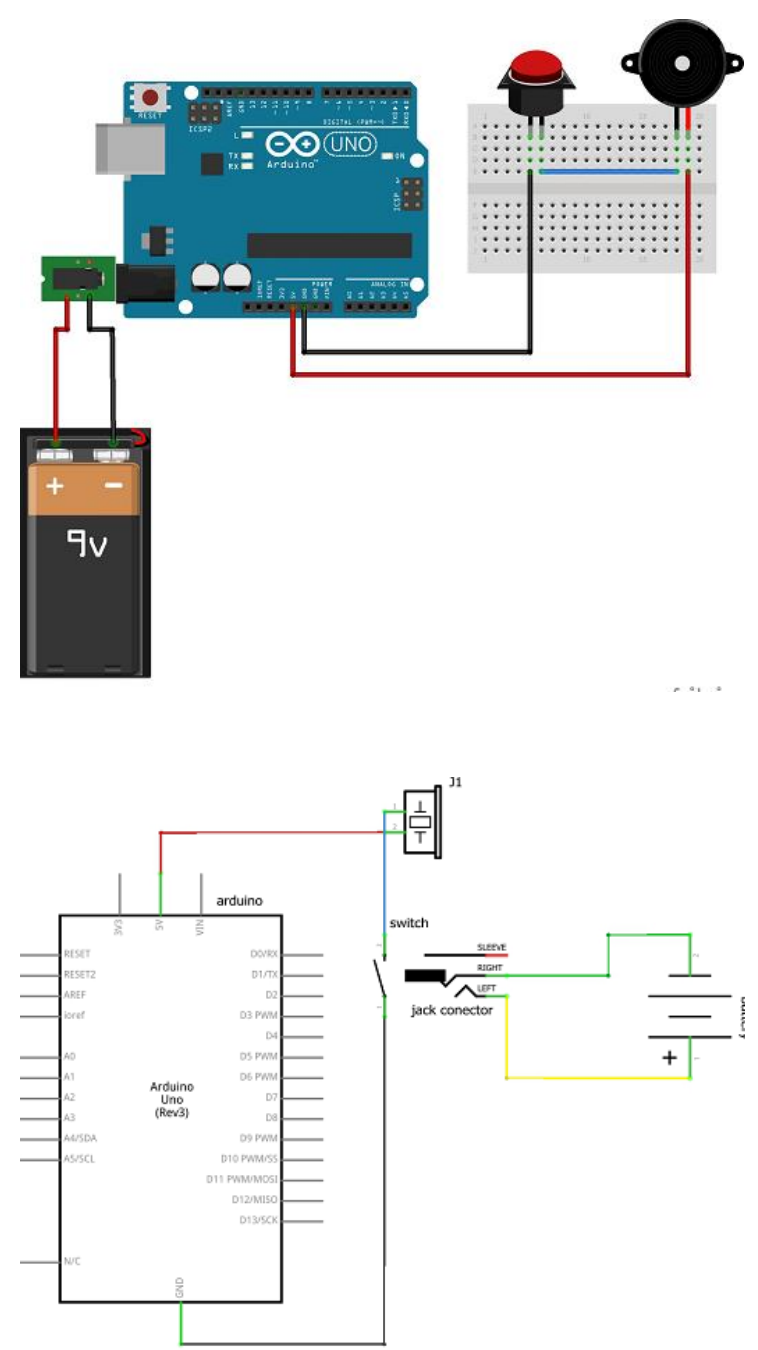

fritzinc

Gambar 14. Diagram Rangkaian Elektronika

Adapun penjelasan program adalah sebagai berikut :

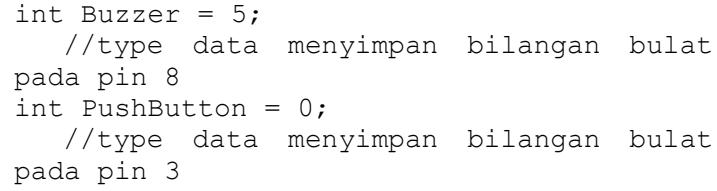


Tabel 2. Hasil pengujian pengalaman

bersama siswa kedua

\begin{tabular}{|c|c|c|c|c|c|}
\hline \multirow[b]{3}{*}{ No. } & \multirow[b]{3}{*}{ PERTANYAAN } & \multicolumn{4}{|c|}{ CALON PENGGUNA KEDUA } \\
\hline & & 4 & 3 & 2 & 1 \\
\hline & & $\begin{array}{c}\text { SANGAT } \\
\text { BAIK }\end{array}$ & BAK & CUKUP & KURANG \\
\hline 1 & $\begin{array}{l}\text { PURWARUPA INI MUDAH } \\
\text { DIGUNAKAN }\end{array}$ & & & & \\
\hline 2 & INOVASI MENARIK & & & & \\
\hline 3 & $\begin{array}{l}\text { INOVASI BERGUNA } \\
\text { UNTUK MASYARAKAT }\end{array}$ & & & & \\
\hline 4 & $\begin{array}{l}\text { INOVASI DAPAT } \\
\text { BERFUNGSI }\end{array}$ & & & & \\
\hline 5 & SISTEM SUDAH OPTIMAL & & & & \\
\hline
\end{tabular}

Inovator yang berbasiskan teknologi sangat sadar bahwa kesuksesan hasil inovasi tidak hanya dilihat dari manfaat dari produk yang akan dihasilkan namun juga perlu memperhatikan faktor pengalaman pengguna., sehingga pengembangan inovasi teknologi tidak lagi hanya tentang mengimplementasikan fitur dan menguji kegunaannya, tetapi juga tentang mendesain produk yang menyenangkan dan mendukung kebutuhan dan nilai-nilai dasar manusia. Dengan demikian, pengalaman pengguna dalam tahapan Proses Desain Rekayasa harus menjadi perhatian utama pengembangan produk (Johnson, Clegg, and Ravden, 1989, p. 255-260).

Tabel 2 dan Tabel 3 menampilkan hasil dari pengujian pengalaman pengguna bersama siswa.menjelaskan bahwa calon pengguna dapat menerima inovasi teknologi alarm fokus dengan baik.. Dengan inovasi ini, maka siswa mampu tetap berkonsentrasi ketika menerima pelajaran didalam kelas.

\section{KESIMPULAN DAN SARAN}

\section{Kesimpulan}

Konsentrasi sangat penting dan dibutuhkan bagi siswa dalam mengikuti proses pembelajaran agar kompetensi yang diharapkan dapat dikuasainya bisa tercapai dengan baik. Begitu pentingnya konsentrasi bagi siswa, sehingga konsentrasi adalah merupakan prasyarat bagi siswa agar dapat belajar dan berhasil mencapai tujuan pembelajaran. dalam penelitian ini ditemukan sebuah masalah yaitu kurangnya konsentrasi siswa didalam belajar. Untuk mengatasi permasalahan ini, diperlukan sebuah fasilitas di sekolah yang berupa inovasi berbasiskan teknologi yang dinamakan Alarm Fokus. Dari hasil pengujian bersama siswa maka dapat didapatkan bahwa inovasi yang dihasilkan baik dan dapat dengan mudah dipergunakan serta sesuai untuk di sekolah.

\section{Saran}

Perguruan tinggi sebagai pusat inovasi memerlukan kerjasama dengan pemerintah daerah untuk dapat mendesiminasikan hasil penelitian. Dengan demikian akan terjadi percepatan penguasaan dan penerapan teknologi di sekolah sehingga mampu meningkatkan kemampuan lulusan sehingga dapat bersaing secara global

\section{UCAPAN TERIMA KASIH}

Terima kasih kepada civitas akademika di jurusan teknik elektro Universitas Maritim Raja Ali Haji (UMRAH) dan redaksi Jurnal Jurnal Ilmiah Pendidikan Teknik Kejuruan 
(JIPTEK) yang telah memberikan kesempatan untuk publikasi.

\section{DAFTAR PUSTAKA}

Anggraini C, and Imaniyati, N. (2017). Fasilitas Belajar Dan Manajemen Kelas Sebagai Determinan Terhadap Prestasi Belajar Siswa, Jurnal Manajerial, Vol. 16, No, 2, p $196-204$

Bastien J M C. (2017). Usability testing: a review of some methodological and technical aspects of the method, International Journal of Medical Informatics. Vol. 79, No. 4, p e18-e23.

Bliss J, and Chancey E T. (2010). The Effects of Alarm System Reliability and Reaction Training Strategy on Alarm Responses, Proceedings of the Human Factors and Ergonomics Society 54th Annual Meeting, p $2248-2252$

Collins P K. (2015). Building a Local Design and Entrepreneurship Ecosystem, Procedia Technology, Vol.20, p 258-262

Design approach - mygov.scot | resources [Daring], Tersedia pada : https://resources.mygov.scot/37f87d5/desi gning-public-services-in-scotland/why-weneed-design-for-public-services-inscotland/design-approach/ [ Diakses : 11 Agustus 2019 ].

Johnson G I, Clegg, C W, and Ravden, S J. (1989). Towards Practical User Experience Evaluation Methods, Jornal of Applied Ergonomics. Vol. 20, No.4, p 255-260

Joore P, and Brezet H. (2015). A Multilevel Design Model: The Mutual Relationship Between Product-Service System
Development And Societal Change Processes, Journal of Cleaner Production, Vol. 97, p 92-105

Muhamad H, Efendi A,, dan Basori, (2019). Pengaruh Fasilitas Belajar Berbasis Teknologi Terhadap Prestasi Belajar Siswa, Jurnal Ilmiah Teknik dan Kejuruan, Vol. 12, No.1, p 56-64

Nusyirwan D. (2017). Engineering Design Process Engineering Student Centered Experience Learning (ESCEL) di Jurusan Teknik Elektro Universitas Maritim Raja Ali Haji (UMRAH). Jurnal Sustainable. Vol. 6, No. 1, p 24-35

Pereira J C, and Russo R F S M. (2018). Design Thinking Integrated in Agile Software Development: A Systematic Literature Review, Procedia Computer Science, Vol. 138, p 775-782

Sekolah Kita [Daring], Tersedia pada : http://referensi.data.kemdikbud.go.id/tabs. php?npsn=11001802 [ Diakses : 11 Agustus 2019 ].

Shergian A, and Immawan T. (2014). Design of Innovative Alarm Clock Made From Bamboo With Kansei Engineering Approach, Agriculture and Agricultural Science Procedia 3, p $184-188$

Tirani A A. (2017). Hubungan Antara Kebiasaan Belajar, Fasilitas Belajar Dan Perhatian Orang Tua Dengan Prestasi Belajar Matematika Siswa Kelas Vii Smp Negeri Se-Kecamatan Pajangan, Jurnal Pendidikan Matematik, Vol. 5, No. 1, p 59-66

Us $\mathrm{T}$, Jensen $\mathrm{M}$, Lind $\mathrm{N}$, and Jorgensen $\mathrm{S}$. (2011). Fundamental Principle of Alarm Design, International Journal of Nuclear 
Safety and Simulation, Vol. 2, No 1, p 4451

Valouch, J. (2012). Integrated Alarm Systems, Researchgate

von Saucken C, Lachner F, and Lindemann U.

(2014). Principles for User Experience

What We Can Learn from Bad Examples,

International Conference on Kansei

Engineering \& Emotion Research

Wagner C, Kawulich B, and Garner M. (2012).

Collecting Data Through Observation,

Doing Social Research: A global context.

McGraw Hill 